Int. J. Electrochem. Sci., 13 (2018) $9642-9653$

International Journal of

ELECTROCHEMICAL

SCIENCE

www.electrochemsci.org

\title{
Cathodic Protection of X100 Pipeline Steel in Simulated Soil Solution
}

\author{
Yingchun Chen, Zuquan Wang, Xinhua Wang ${ }^{*}$ Xuting Song, Cheng Xu \\ College of Mechanical Engineering and Applied Electronics Technology, Beijing University of \\ Technology, Beijing, China \\ *E-mail: paper_bgdjd103@163.com
}

doi: $10.20964 / 2018.10 .23$

Received: 8 June 2018 / Accepted: 20 July 2018 / Published: 1 September 2018

\begin{abstract}
Generally, the basic parameters of conventional cathodic protection design mostly rely on theoretical or empirical approximate formulas. An over protection phenomenon has emerged for pipeline systems with large scale differences in soil environment. This paper investigated the basic parameters of the electric cathodic protection under three types of simulated soil solution environments (Korla station, Lhasa station and Yingtan station) for X100 high strength pipeline steel by using the technology of electrochemical impedance spectroscopy (EIS) combined with polarization curves. The results showed that the EIS and polarization curves can help determine the basic parameters for X100 high strength pipeline steel cathodic protection under the above three simulated soil solution environments. Also, the changing characteristics of charge transfer resistance $\left(R_{t}\right)$ and cathode potential change $(E)$ changes, can be achieved by fitting EIS results: with negative potential shifting, $\mathrm{R}_{\mathrm{t}}$ appeared a maxima value; Hydrogen evolution reaction started at the stage when $R_{t}<1000 \Omega \cdot \mathrm{cm}^{2}$; For X100 high strength pipeline steel under different simulated soil solution environments at Korla station, Lhasa station and Yingtan station, the size of hydrogen evolution potential was successively reduced.
\end{abstract}

Keywords: X100 pipeline steel; cathodic protection; polarization curves; EIS

\section{$\underline{\text { FULL TEXT }}$}

(C) 2018 The Authors. Published by ESG (www.electrochemsci.org). This article is an open access article distributed under the terms and conditions of the Creative Commons Attribution license (http://creativecommons.org/licenses/by/4.0/). 